\title{
Pesquisas em sistemas de apoio à decisão para orientação de transfusão plaquetária
}

\author{
Victor P. B. de Carvalho', Fábio N. T. Alvim², Fernanda Azevedo Silva ${ }^{2}$, Flávio \\ Luiz Seixas ${ }^{1}$ \\ ${ }^{1}$ Instituto de Computação - Universidade Federal Fluminense (UFF) - 24.210-346 - \\ Niterói - RJ - Brasil \\ ${ }^{2}$ Hemocentro - Hospital Universitário Antônio Pedro (Ebeserh/UFF) - 24.033-900 - \\ Niterói - RJ - Brasil \\ victorproencadid.uff.br, fabio natario@hotmail.com,
}

Abstract. Worldwide, blood centers have problems with the stock of blood. Because of transfusions that could be avoided occur, we need to optimize the use of blood. Besides, such transfusions can lead to fatal adverse reactions. This article describes a Scientific Initiation project for the development of a decision support system for platelet transfusion that aims at advising the doctor in relation to the transfusion, and so to increase the rational use of platelets and a reduction in the number of adverse reactions.

Resumo. Mundialmente, hemocentros têm problemas em relação ao estoque de sangue. Devido ao fato de que ocorrem transfusões que poderiam ser evitadas, faz-se necessária uma otimização na utilização do sangue. Além disso, tais transfusões podem gerar reações adversas fatais. Este artigo descreve um projeto de Iniciação Científica de desenvolvimento de um sistema de apoio à decisão para transfusão plaquetária com o objetivo de aconselhar o médico em relação à transfusão, almejando-se aumentar o uso racional de plaquetas e uma redução no número de reações adversas.

\section{Introdução}

O sangue e os componentes do tecido sanguíneo humano têm se tornado imprescindíveis para a saúde pública (SOUZA; SANTORO, 2019). Segundo Rodrigues e Reibnitz (2011), os hemocentros possuem dificuldades em manter o estoque de sangue para atender às necessidades específicas e emergenciais, e as estatísticas mundiais revelam que as doações de sangue não acompanham o aumento de transfusões. Enquanto a Organização Mundial da Saúde tem como meta que cada país tenha cerca de 3\% de sua população doadora (VERDÉLIO, 2017), 1,6\% da população brasileira doa sangue (VENTURA, 2019). Isso mostra que o Brasil está longe de alcançar a meta de população doadora. Tendo em mente que doar sangue é um ato que pode salvar as vidas de milhares de pessoas (MIRZA et al., 2015) e que há uma escassez de doações sanguíneas, faz-se necessário administrar os bancos de sangue brasileiros de forma a otimizá-los, com o intuito de atender mais eficientemente a população. Associado ao baixo quantitativo de doadores, a transfusão de sangue é utilizada em excesso, o que pode causar agravos aos pacientes, e o desenvolvimento de ferramentas que ajudem a tomada de decisão médica quanto à necessidade de transfusão tem se mostrado efetivo na redução das transfusões desnecessárias (KASSAKIAN et al., 2016). 
No Hospital Universitário Antônio Pedro (HUAP), situado na cidade de Niterói (RJ), são recebidos muitos pedidos de transfusão de sangue. Em paralelo a isso, há insuficiência de estoque de bolsas sanguíneas em alguns momentos, fazendo com que este precise ser bem administrado e otimizado. Além disso, em certos casos, são feitas transfusões que poderiam ser evitadas. Algumas transfusões podem ocasionar reações adversas, podendo até ser fatais, e o consumo racional do hemocomponente poderá melhorar a situação do estoque do Hemonúcleo.

Neste artigo, propõe-se o desenvolvimento de um aplicativo que seja capaz de orientar o profissional responsável no processo decisório da indicação transfusional. $\mathrm{O}$ aplicativo seguirá uma sequência de perguntas baseadas em diretrizes clínicas e publicações científicas que fundamentarão o aconselhamento fornecido pelo mesmo. A partir da análise das informações clínicas e resultados de exames laboratoriais do paciente, o aplicativo chegará a uma sugestão mais precisa sobre a questão transfusional. Deste modo, espera-se uma redução do número de transfusões e, consequentemente, de reações adversas quando sistema for utilizado.

O artigo está dividido em seções. A Seção 2 mostra os trabalhos relacionados. A Seção 3 descreve a metodologia e análise de sistema. A Seção 4 expõe a modelagem. A Seção 5 detalha as telas de protótipo. A Seção 6 apresenta a conclusão. A Seção 7 expressa os agradecimentos e a Seção 8 informa as referências.

\section{Trabalhos Relacionados}

Por mais que médicos de todas as especialidades sejam bem treinados e tenham amplo conhecimento, eles são suscetíveis a erros e podem tomar decisões ou conceder diagnósticos errados. A partir dessa informação, criaram-se sistemas de apoio à decisão clínica, os quais podem ajudar médicos a determinarem diagnósticos mais rapidamente e com mais segurança.

$\mathrm{O}$ aplicativo Ada segue o conceito de chat, permitindo que seus usuários respondam a várias perguntas, e providencia sugestão de diagnóstico baseada nas informações fornecidas (LAUMER; MAIER; GLUBER, 2019). Apesar da semelhança em relação ao diagnóstico ser dado após o usuário responder uma sequência de perguntas, o projeto descrito neste artigo possui como objetivo ajudar na tomada de decisão sobre a transfusão de concentrado de plaquetas, fornecendo não uma sugestão de diagnóstico, mas sim uma orientação no tocante à questão transfusional.

Segundo Nash (2010), o sistema Isabel gera, a partir de dados extraídos da queixa principal dos pacientes, uma breve lista de diagnósticos mais prováveis para o caso e, além disso, Isabel também direciona o clínico à literatura relevante sobre essas condições. Diferentemente do sistema Isabel que colhe informações sobre a queixa do paciente e informa uma lista de diagnósticos, o aplicativo projetado terá como foco orientar o médico em relação à transfusão plaquetária, colhendo dados clínicos e laboratoriais relevantes sobre a questão.

$\mathrm{O}$ aplicativo descrito neste artigo tem como funcionalidade principal o aconselhamento em relação à transfusão plaquetária. Ele terá uma sequência de perguntas relacionadas à transfusão de plaquetas que devem ser respondidas pelo usuário. Ao terminar de responder às questões postas no software, a orientação transfusional será informada em conjunto com as publicações científicas que basearam a tomada de decisão. 


\section{Metodologia e análise de sistema}

A metodologia que é usada é a de desenvolvimento ágil. $\mathrm{O}$ uso de metodologias ágeis permite que desenvolvedores de software produzam softwares de maior qualidade em menor período de tempo (LIVERMORE, 2008). Dessa forma, o cliente tem contato com o software mais rapidamente, criando oportunidade para ser feito um teste de usabilidade em um menor espaço de tempo.

A primeira etapa tem foco no desenvolvimento da primeira versão do aplicativo, sendo essa fundamentada nos requisitos mínimos exigidos. São desenvolvidas as funções de fornecimento perguntas, orientação transfusional e de fornecimento de links para os artigos que baseiam essa orientação. Após isso, é feito um teste de usabilidade para detectar problemas ou pontos que devem ser melhorados. A partir dessa avaliação, iniciase a segunda etapa de desenvolvimento, que tem foco na melhoria dos aspectos do aplicativo e código fonte. Tais melhorias são fundamentadas nos resultados do teste de usabilidade e cobertura de testes. Além disso, nesta etapa busca-se utilizar um repositório e gestão de configuração para que se possa fazer integração contínua.

Para a construção do aplicativo, foram feitas reuniões com o médico hematologista. A partir dessas reuniões, chegou-se aos requisitos do sistema. Em relação aos requisitos não funcionais, concluiu-se que o mesmo deve se apresentar na forma de aplicativo, ser multiplataforma e deve também fornecer links para os artigos que basearam o aconselhamento. Em relação aos requisitos funcionais, o aplicativo deve fornecer perguntas relacionadas à questão de transfusão sanguínea e deve ser capaz de aconselhar se a transfusão é necessária. As recomendações feitas no aplicativo são baseadas no Guia para o uso de hemocomponentes (BRASIL, 2015), que contém indicações e contraindicações de hemocomponentes. Tais recomendações são reforçadas com diferentes publicações científicas selecionadas pelo médico hematologista relacionadas ao tema.

\section{Modelagem}

Os diagramas desenvolvidos foram diagrama de atividades, diagrama de casos de uso e diagrama de classes. Os diagramas não foram apresentados no artigo devido à limitação de páginas. A sequência de ações contidas no diagrama de atividades percorre a seguinte estrutura narrativa: o médico prescritor examina o paciente (exame de imagem, clínico e laboratorial), responde perguntas relacionadas ao estado clínico ou laboratorial do paciente (questão transfusional) e, após o aconselhamento, decide se vai efetuar a transfusão de sangue.

Ao se desenvolver o diagrama de casos de uso, chegou-se à conclusão de que o médico prescritor é o ator do sistema. Foram mapeados os seguintes casos de uso: cadastrar usuário, efetuar login, alterar dados cadastrais, consultar necessidade de transfusão e responder perguntas sobre a transfusão sanguínea. A sequência de ocorrência dos casos de uso cumpre a estrutura narrativa posta a seguir: o médico, como usuário do aplicativo, deverá se cadastrar e efetuar login, para que ele tenha acesso às principais funções do sistema. Em seguida, ele deverá consultar sobre a necessidade de transfusão ao responder perguntas relacionadas ao paciente sobre transfusão sanguínea. Ao terminar a consulta, o aplicativo deverá aconselhar se há necessidade de transfusão.

No Diagrama de Classes é possível identificar um conjunto de perguntas e respostas que é respondido pelo médico. Cada médico pode responder a um conjunto de testes e um teste pode ser respondido por um conjunto de médicos. Além disso, um teste 
pode possuir diversas perguntas e respostas, sendo essas perguntas passíveis de terem variadas opções de respostas.

\section{Protótipo de telas}

Na tela de autenticação do usuário, o usuário deverá informar seu nome de usuário e senha para que o mesmo efetue login no aplicativo. Na tela de cadastro do usuário, o usuário deverá informar seu nome completo, código do CRM, nome de usuário e senha para que o mesmo efetue cadastro no aplicativo. Na tela de alteração de dados cadastrais, o usuário poderá informar seu nome completo, código do CRM, nome de usuário ou senha e, após fornecer o(s) novo(s) dado(s), será capaz de alterar os seus dados cadastrais. Na tela principal da aplicação, sendo ela a de seleção de situação do paciente, o usuário poderá selecionar o caso em que o paciente se encontra e, a partir disso, consultar se há a necessidade de transfusão.

Dado o fato de que são muitas telas e muitas possibilidades de seleção das respostas, apresenta-se um exemplo de uma situação para que se compreenda o funcionamento do protótipo. Ao selecionar a situação "Trombocitopenia hipoproliferativa induzida por terapias" na tela de seleção de situação do paciente, o usuário primeiramente informará se o paciente apresenta sangramento ativo. Caso o mesmo responda "NÃO", o aplicativo apresentará uma nova tela, pedindo que o usuário informe em qual situação o paciente se encontra dentro do caso selecionado.

Considerando que o usuário selecione "Febre", uma nova tela será exibida, na qual o usuário informará a contagem de plaquetas do paciente. Caso o usuário selecione

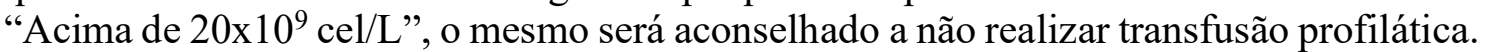
Caso o usuário selecione "Menor ou igual a $20 \times 10^{9} \mathrm{cel} / \mathrm{L}$ ", ele será aconselhado a realizar transfusão profilática.

Em relação à orientação transfusional, existem 6 aconselhamentos possíveis de serem dados pelo aplicativo após o usuário responder às perguntas. É possível ser aconselhado a: 1) realizar transfusão profilática, 2) não realizar transfusão profilática, 3) manter paciente em observação, 4) monitorar níveis de plaquetas, 5) transfundir plaquetas para manter o número maior que $100.000 \times 10^{6} \mathrm{cel} / \mathrm{L}$ e 6 ) considerar transfusão profilática levando em conta o tempo de cirurgia ou disfunção plaquetária. Tais aconselhamentos resultam, basicamente, em 2 resultados: transfusão aconselhada ou transfusão não aconselhada. Três dos aconselhamentos estão postos abaixo para exemplificar como são as telas de aconselhamento do protótipo. Nas telas, abaixo de cada aconselhamento, encontram-se os links referentes aos artigos científicos que basearam o mesmo. 
A Figura 1 representa as telas de aconselhamentos. Nela, a tela "a" representa a tela de indicação de transfusão profilática, sendo o usuário aconselhado a transfundir profilaticamente 1 dose (aférese ou pool de plaquetas). A tela "b" representa a tela de não indicação de transfusão profilática, sendo o usuário aconselhado a não transfundir profilaticamente. A tela "c" representa a tela de aconselhamento de monitorar níveis de plaquetas, sendo o usuário aconselhado a não transfundir profilaticamente, informando-o para monitorar os níveis de plaqueta do paciente analisado.

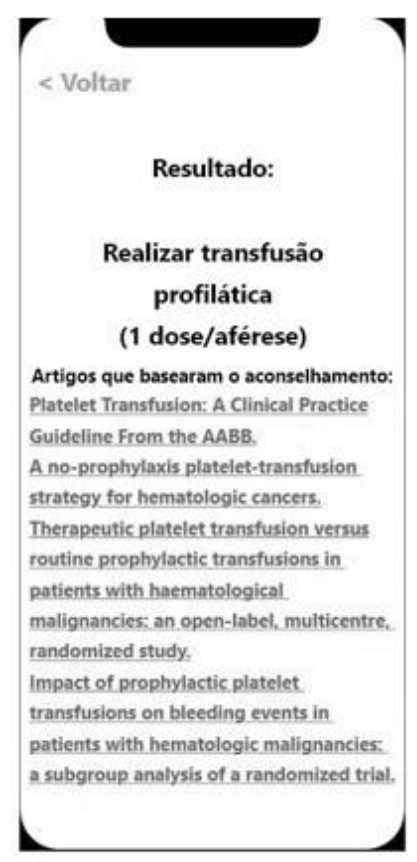

a

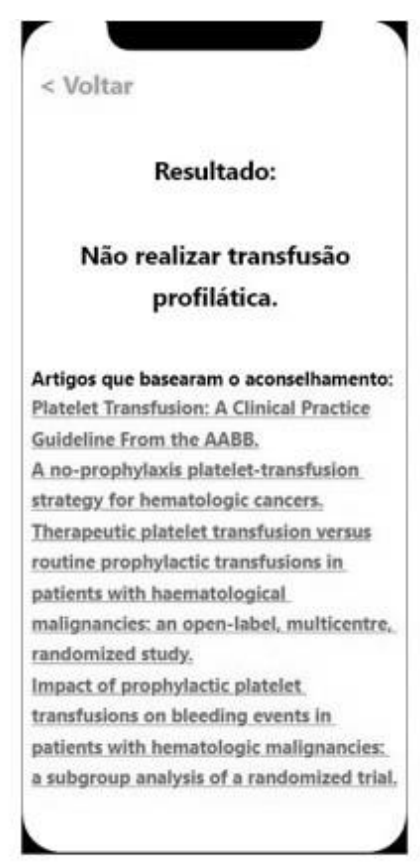

b

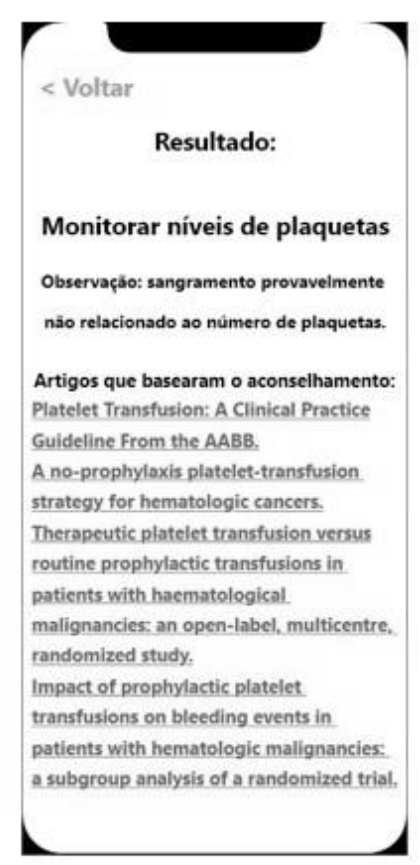

C

Figura 1. Telas de aconselhamento

\section{Conclusão}

Devido ao programa de incentivo Patient Blood Management, que estimula o uso de protocolos restritivos de transfusão e a necessidade de transfundir apenas o quantitativo mínimo necessário de sangue, torna-se importante auxiliar o médico na tomada de decisão sobre a transfusão. Para ajudar nesta situação, a tecnologia da informação pode ser uma aliada. Neste artigo, propôs-se o desenvolvimento de um aplicativo que auxilie na tomada de decisão do médico prescritor, aconselhando sobre a necessidade de uma transfusão plaquetária.

Até o momento, foi produzida a documentação do software. Além disso, também foram descritos detalhadamente os requisitos funcionais e não funcionais do aplicativo. A conclusão de tais atividades permite iniciar a próxima etapa do projeto, a qual é o desenvolvimento do aplicativo. Os próximos passos serão o desenvolvimento da primeira versão do aplicativo, baseado na documentação produzida, e o teste de usabilidade, etapa em que será avaliada a experiência do usuário com o intuito de se descobrir problemas ou pontos de melhorias. A partir deste teste de usabilidade, o aplicativo será aprimorado. Espera-se, com o desenvolvimento deste aplicativo, um aumento do uso racional de plaquetas, melhora do estoque de hemocomponentes e consequentemente uma diminuição no número de reações adversas nos casos em que o sistema for usado. 


\section{Agradecimentos}

Este projeto é parcialmente financiado pelo Conselho Nacional de Desenvolvimento Científico e Tecnológico $(\mathrm{CNPq})$ através do fornecimento de bolsa de Iniciação Científica ao aluno.

\section{Referências}

BRASIL. Ministério da Saúde. Secretaria de Atenção à Saúde. Departamento de Atenção Especializada. Guia para o uso de hemocomponentes. 2 ed. Brasília: Ministério da Saúde, 2015.

KASSAKIAN, Steven Z. et al. Clinical decision support reduces overuse of red blood cell transfusions: interrupted time series analysis. The American journal of medicine, v. 129, n. 6, p. 636. e13-636. e20, 2016.

LAUMER, Sven; MAIER, Christian; GUBLER, Fabian Tobias. Chatbot acceptance in healthcare: Explaining user adoption of conversational agents for disease diagnosis. ECIS 2019 Proceedings, p. 1-2, 2019.

LIVERMORE, Jeffrey A. Factors that Significantly Impact the Implementation of an Agile Software Development Methodology. Journal of Software, v. 3, n. 4, p. 31, 2008 .

MIRZA, Humayun et al. Blood safety and donation knowledge, attitude and practice (KAP) among 1st year medical students at LMDC, Lahore. Pakistan Journal of Medical \& Health Sciences, v. 9, n. 3, p. 992, 2015.

NASH, David B. Isabel, a new diagnostic aid for the 21st century. Pharmacy and Therapeutics, v. 35, n. 12, p. 651, 2010.

RODRIGUES, Rosane Suely May; REIBNITZ, Kenya Schmidt. Estratégias de captação de doadores de sangue: uma revisão integrativa da literatura. Texto \& ContextoEnfermagem, v. 20, n. 2, p. 385, 2011.

SOUZA, Mariluce Karla Bomfim de; SANTORO, Pablo. Desafios e estratégias para doação de sangue e autossuficiência sob perspectivas regionais da Espanha e do Brasil. Cadernos Saúde Coletiva, v. 27, n. 2, p. 196, 2019.

VENTURA, Cristiane. Dezesseis a cada mil brasileiros doam sangue. Ministério da Saúde, $[S . \quad l],. \quad 14 \quad$ jun. 2019. Disponível em: https://www.saude.gov.br/noticias/agencia-saude/45520-dezesseis-a-cada-milbrasileiros-fazem-doacao-de-sangue. Acesso em: 28 fev. 2020.

VERDÉLIO, Andreia. Doação de sangue: $1,8 \%$ da população brasileira doa sangue; meta da OMS é 3\%. Agência Brasil, Brasília, 14 jun. 2017. Disponível em: https://agenciabrasil.ebc.com.br/geral/noticia/2017-06/doacao-de-sangue-18-dapopulacao-brasileira-doa-sangue-meta-da-oms-e-3. Acesso em: 29 fev. 2020. 